\title{
Nostro Mundo: espacios extraordinarios en la poesía de Néstor Perlongher.
}

\section{Nostro Mundo: Extraordinary Spaces in the Poetry of Néstor Perlongher.}

\section{Resumen}

Este ensayo analiza el rol de lo que denomino como un exotismo queer en la poesía de Néstor Perlongher. Este exotismo queer deriva de una indagación poética en torno a espacios extraños, poco familiares, como escenarios potenciales de sociabilidades alternativas. Retomando planteos de José Muñoz sobre utopismo queer y las relecturas de Sylvia Molloy en clave queer en torno al orientalismo, propongo un recorrido por la poesía de Perlongher desde su participación en la revista Somos del Frente de Liberación Homosexual argentino, a principios de los setenta, hasta su aporte "neobarroso" en el poemario Parque Lezama (1990). En todos estos casos, la exploración de sexualidades y sociabilidades disidentes conlleva una reexaminación crítica de un "aquí y ahora" visto como opresivo y la formulación de un espacio exótico queer de rasgos utópicos.

Palabras claves Queer, disidencia sexual, espacio, geografía, activism, exotismo, utopismo, orientalismo.

\begin{abstract}
This essay examines the role played by what I call a queer exoticism in the poetry of Néstor Perlongher. This queer exoticism derives from a poetic search for strange, unfamiliar spaces with the potentiality to harbor or give rise to alternative sociabilities. Drawing on José Muñoz's notion of a queer utopianism and Sylvia Molloy's explorations of a queer
\end{abstract}


CATEDRAL TOMADA: Revista de crítica literaria latinoamericana / Journal of Latin American Literary Criticism Nostro Mundo: espacios extraordinarios en la poesía de Néstor Perlongher.

Orientalism, I analyze Perlongher's poetry from his participation in the magazine Somos, published by the Argentine Frente de Liberación Homosexual in the early 1970s, to his NeoBaroque --or "Neobarroso"-- poetry in Parque Lezama (1990). In all these cases, the exploration of dissident sexualities and sociabilities entails a critical reexamination of a "here and now" seen as oppressive and the formulation of an exotic queer space with utopian features.

Keywords Queer, Space, Geography, Political Activism, Exoticism, Utopianism, Orientalism.

El criterio para elegir es complejo. En principio todo tiene que brillar [...] En segundo lugar, tomar siempre algo que parezca más difícil: cuando estoy asociando, evitar siempre la asociación fácil o la asociación supuesta; elegir la más rara, la más linda, la más joyesca. Para decirlo de otro modo, a mí me gustan las películas donde aparecen elefantes, sheiks, caimanes, castillos medievales; no las películas al estilo Los de la mesa diez, ese tipo de teatro argentino donde siempre se está en torno de una mesa, con un sifón y un plato de tallarines. Lo poético tiene que encontrar un punto de fuga en cualquier situación. Flujos de deseo. (Papeles insumisos $351)^{1}$

Esta cita de Néstor Perlongher enlaza de modo sucinto por lo menos dos aspectos clave en su poesía, presentes además en sus ensayos sobre el neobarroco: la afición por el brillo, por un lado, y la apuesta por lo "difícil", entendido como lo extraño y, finalmente, lo exótico, por el otro. El criterio estético de Perlongher rehúye y se desvía del facilismo costumbrista, aquí codificado en términos que nos remiten a lo nacional-popular, y que no casualmente se ordenan imaginariamente como un entorno familiar. El planteo sobre lo familiar parece condensar ambos sentidos de la palabra: como lo conocido (lo propio -habla de teatro argentino-, lo dado, lo que forma parte del entorno inmediato y es, por ello, fácil de incorporar en la propia poesía) pero también en referencia al núcleo familiar, ya que para un sinfín de obras teatrales, relatos y series televisivas de la

${ }^{1}$ Extracto de la entrevista realizada a Néstor Perlongher por Guillermo Saavedra, publicada originalmente en el suplemento "Cultura y Nación" del diario Clarín (26 de diciembre de 1991) e incluida en la edición a cargo de Adrián Cangi y Reinaldo Jiménez Papeles insumisos, Santiago Arcos, 2004. 
época lo que la mesa y el "plato de tallarines" congregan son los miembros de la familia, representando casi mecánicamente cada uno sus roles consensuados. En este contexto, pues, el neobarroco o neobarroso perlonghereano permitiría una "fuga", a la zaga de aquellos "flujos de deseo".

Es para estos años, a mediados de la década del ochenta, que Perlongher incorpora en su poesía de manera más o menos programática algunas de las lecciones aprendidas de Deleuze y Guattari, mientras se aboca progresivamente a la lectura de José Lezama Lima. Sin embargo, más que ahondar en el nomadismo en la poesía y los ensayos del Perlongher neobarroco - una clave de lectura sin duda válida y fructífera, pero en todo caso ampliamente transitada-, lo que me interesa en este ensayo es aquel peculiar exotismo consignado en la cita como una enumeración ("elefantes, sheiks, caimanes, castillos medievales") en tanto característico del neobarroco y, en particular, de la poesía de Perlongher.

El exotismo perlonghereano funciona, sobre todo, como el rechazo de un aquí y ahora visto como opresivo y una apuesta por espacios remotos (nunca claramente descriptos ni mucho menos ubicados y delimitados) donde las normas "familiares" ceden ante otras posibles relaciones sociales, subjetividades y formas de vida. Este exotismo neobarroco debe, por ello, ser puesto en serie con otras exploraciones a lo largo de la vida y obra de Perlongher en que un cierto utopismo queer conlleva una imaginación crítica en torno a las coordenadas temporoespaciales existentes. En otras palabras, la pregunta por la comunidad queer -una comunidad siempre en proceso, nunca del todo conformada- conlleva en Perlongher una examinación sobre los ordenamientos heteronormativos del tiempo y del espacio y la proyección imaginaria de sociabilidades alternativas que desafían esos ordenamientos.

Del mismo modo que Elizabeth Freeman habla de temporalidades queer que van a contrapelo de la "crononormatividad" como régimen biopolítico orientado a la reproducción y a la producción capitalista, este ensayo busca retomar discusiones sobre espacialidades queer que de alguna manera rechazan los paradigmas heteronormativos que delimitan territorios $\mathrm{y}$ ordenan la 
circulación de cuerpos a escala local, regional y global. La poesía de Perlongher, y en especial su exotismo en clave queer, es una excelente oportunidad para analizar los alcances posibles de una imaginación espacial ligada a una exploración sobre comunidades alternativas.

Como señala Gordon Brent Ingram, la reflexión en torno al espacio se vuelve totalmente necesaria para dar cuenta de la experiencia de disidentes sexuales que han migrado a zonas urbanas para formar parte de un estilo de vida acorde a su deseo, que han aprendido a moverse por ese mismo tejido urbano a menudo evitando hostilidades o que han desarrollado nuevas territorialidades como los llamados "barrios rosa". Además, agrega Brent Ingram,

In every queerscape there is a current of imagination, of only partially recognized and territorialized desire [...] Nicole Brossard recently described a fantasy for a cruising park 'for women only' in Barcelona. Similarly, Annamarie Jagose has argued that the word 'lesbian' always has embodied a vision of utopian space and a displacement of patriarchal sites. (38)

Es esa misma dimensión utópica queer la que llevó a sus últimas consecuencias José Muñoz, retomando la oposición de Ernst Bloch entre utopías abstractas y concretas, y valorando estas últimas como aquellas que se remiten a "historically situated struggles" (3) y a una comunidad potencial o ya existente. De lo que se trata, para Muñoz, es de contraponer a un pensamiento pesimista y conformista la propuesta de una disidencia sexual entendida como horizonte, como futuro "potencial". De ahí esa especie de slogan que abre su Cruising Utopia y se repite, como leitmotiv, a lo largo del libro: "Queerness is not yet here" (1). Lo que vale, pues, es la capacidad del utopismo queer de rechazar el estado de cosas de un aquí y ahora, abrir una instancia crítica e imaginar otras formas de vida: 
Agamben's reading of Aristotle's De Anima makes the crucial point that the opposition between potentiality and actuality is a structuring binarism in Western metaphysics. Unlike a possibility, a thing that simply might happen, a potentiality is a certain mode of nonbeing that is eminent, a thing that is present but not actually existing in the present tense. Looking at a poem written in the 1960s, I see a certain potentiality, which at that point had not been fully manifested, a relational field where men could love each other outside the institutions of heterosexuality and share a world through the act of drinking a beverage with each other [...] Bloch would posit that such utopian feelings can and regularly will be disappointed. They are nonetheless indispensable to the fact of imagining transformation. (9)

A pesar de la referencia espacial en la frase antes citada ("here"), el énfasis de Muñoz está claramente puesto en lo temporal. Sin embargo el mismo epígrafe, la cita de Oscar Wilde con la que abre su introducción, arrastra un fuerte contenido espacial (geográfico): "A map of the world that does not include utopia is not worth glancing at" (1). La única referencia pormenorizada de parte de Muñoz en torno a los espacios de este utopismo queer es, en verdad, muy valiosa e involucra esta suerte de mapamundi. Según Muñoz, el rechazo del "aquí" de la utopía queer por lo general implica una tensión con los marcos nacionales y puede, por ello, recurrir a una escala "global". Muñoz repara, no obstante, en el hecho de que la globalización "defines a worldwide system of manufactured asymmetry and ravenous exploitation" (29). Por eso, para pensar este utopismo queer que trasciende el ámbito nacional estatal retoma, en cambio, la experiencia transnacional de la agrupación Third World Gay Revolution, una deriva del Gay Liberation Front surgida a comienzos de los setenta y conformada mayormente por personas de color que buscaban establecer alianzas con movimientos queer de otras partes del mundo $\mathrm{y}$, especialmente, operar a partir de una política de 
CATEDRAL TomadA: Revista de crítica literaria latinoamericana / Journal of Latin American Literary Criticism Nostro Mundo: espacios extraordinarios en la poesía de Néstor Perlongher.

solidaridad con las diversas luchas por la descolonización a lo largo y ancho del planeta.

Hay algo en común entre la frase de Wilde y esa suerte de ars poética anticostumbrista de Perlongher. Eso que merece o no ser observado en Wilde reaparece en el gusto por lo joyesco en Perlongher y se cifra, en cambos casos, como rechazo a lo ya conocido, lo ya dado, a la representación realista en un mapa o un poema. Y en verdad hay en Perlongher lo que se podría denominar como una dimensión utópica queer -siguiendo el planteo de Muñoz- cuyas implicancias resuenan especialmente en el plano espacial o, incluso, geográfico. De lo que se trata, una y otra vez, a lo largo de las exploraciones poético-políticas de Perlongher desde comienzos de los setenta hasta - por lo menos- fines de lo ochenta, es de proyectar espacios potenciales para una comunidad queer en ciernes.

Si Muñoz presta atención al utopismo ligado Stonewall y a experiencias como el Third World Gay Revolution, además de múltiples materiales estéticos, en el caso de Perlongher, su participación en el Frente de Liberación Homosexual argentino puede ser considerada un precedente fundamental en los modos en que en su poesía se anudaron disidencia sexual y una interrogación en torno al espacio. Como explica Cecilia Palmeiro, “[la] libidinización de lo social y [la] circulación pulsional [...] como energías de desestabilización de normas civilizadas", características de la obra de Perlongher como antropólogo callejero y escritor, surgen como "certeza[s] adquirida[s] en la experiencia de los años de militancia en los setenta [y] reaparecerá[n] una década más tarde articulada[s] en una investigación del cuerpo en vibración a través de lo poético" (30-31). De ahí que la pregunta por el espacio surgida en el marco de proyectos comunitarios queer (como diría Muñoz, proyectos utópicos o potenciales) urdidos recurrentemente en la poética perlonghereana, merece ser rastreada, también, en esa experiencia militante.

Inspirado en parte en experiencias similares en otras partes del mundo, entre las que se destacan "la lucha antirrepresiva de Stonewall y [...] las 
contestaciones al poder de Mayo del 68" en Francia (Palmeiro 31), el activismo del FLH se ubica, ya desde su inicio a principios de lo setenta, entre la afiliación argentina y las redes de solidaridad transnacionales en las que se inserta. Cualquiera de los números de Somos, el órgano de difusión del Frente, da cuenta de los contactos asiduos que el FLH mantenía con agrupaciones semejantes en San Francisco, Nueva York, Cataluña y Francia. También ocupaban un lugar importante en la revista las coberturas sobre la situación de los homosexuales en otros países del mundo, especialmente los del llamado Primer Mundo y los latinoamericanos. De alguna forma el FLH retoma una de las preocupaciones signadas, ya, en el nombre de Nuestro Mundo, la agrupación homosexual pionera en la que se inspira y que, de hecho, se incorpora más tarde, de la mano de Héctor Anabitarte y otros, como parte integrante del Frente. Aquel nombre-consigna, Nuestro Mundo, refleja la intención de formar una comunidad en primera persona del plural -y un contrapúblico queer, para citar a Michael Warner, a través de boletines que reencarnan luego en la revista Somos-, pero ese "mundo" puede significar tanto el ambiente (el "mundillo") homosexual más o menos local como, también, el mundo, como si lo que se reivindicara fuera la presencia de disidentes sexuales en todas partes del mundo y su derecho a reclamar "el mundo" como propio (el mundo es también nuestro mundo sería una manera de parafrasearlo).

¿Cómo se inscribe la comunidad homosexual en ciernes en términos espaciales? ¿Dónde se desarrolla ese tipo de sociabilidad, que por lo general permanece invisible y resulta, por ende, a priori inhallable? ¿Hasta qué punto debe o puede pensarse en términos nacionales y hasta qué punto los homosexuales argentinos forman parte, más bien, de una comunidad internacional? Estas son preguntas que surgen de una lectura de los ejemplares de Somos, publicados en forma de fotocopias y distribuidos clandestinamente entre 1973 y el advenimiento de la dictadura en 1976, y en los que Perlongher tuvo un rol muy activo como editor y colaborador asiduo siempre con seudónimo. El primer editorial refleja, ya, aquel utopismo queer al que nos referíamos, cifrado en términos espaciales: 
"Una vez, alguno de nosotros soñó con un lugar. Era un lugar abierto, espaciado. Había una avenida que se llamaba LIBERTAD” (Somos 2).

Además de las notas de claro contenido político, análisis y manifiestos anti-heterosexistas o anti-patriarcales, consejos para lidiar con la persecución policial, secciones humorísticas en clave camp, coberturas sobre la disidencia sexual en diversos contextos nacionales, hay una zona más bien poética de la revista Somos que también refleja esta preocupación por el espacio. En el poema "Yo soy" (Alexis 38) ${ }^{2}$, por ejemplo, el verbo ser que da nombre a la revista $-y$ que, aunque deduzcamos que convoca el predicativo "homosexuales", tal vez debido a la censura de la época queda inevitablemente en suspenso- se formula en singular pero se desarma y transmuta sin dejar una idea clara de aquella subjetividad que, por el contexto de la revista, asumimos como homosexual:

Yo soy la pulpa que en silencio / alimenta la vida de las hierbas; / soy el sombrío aullido de los lobos / que en las noches invernales / se pierde entre el frío estoico de la nieve; / soy el arbusto adormecido que murmura / entre las rocas; / soy la muchedumbre que conserva veneno en sus pulmones / y soy el moribundo que escucha el zumbido nocturno / de la muerte. / Aquí estoy yo!, viejo alquitrán de calles descarnadas, / cálida fragancia de cuerpos desnudos: soy / la violencia enloquecida que goza su contacto. / Soy del perro, los ojos morbosos / que anhelan las mujeres / y soy el sexo de los hombres / que aman a los hombres; / soy la mirada ardiente que destruye antiguos muros / y soy el fuego vivo que asola las catedrales; / soy mi propia carne, roja y sedienta, / y soy la sangre que corre por mis venas. (39)

\footnotetext{
${ }^{2}$ Firmado por Alexis, ningún crítico hasta ahora ha atribuido este poema a ningún integrante del FLH ni a ningún escritor allegado al Frente.
} 
Más interesante aún es aquel “Aquí estoy yo!”, que casi como un grito en medio del poema busca dar cuenta de una localización concreta pero que rápidamente se desdibuja en la medida en que sujeto y espacio parecen entremezclarse -y además, el recorrido continuo por diferentes espacios hacen de ese “aquí estoy yo" una suerte de deíctico móvil y, finalmente, inaprehensible. En una revista que parecería afirmar una identidad homosexual y una visibilidad que diera cuenta de una posible localización de esa identidad homosexual (pensemos, paradigmáticamente, en el lema de Act Up "We are queer, we are here, get used to it"), ciertas zonas (y especialmente las contribuciones literarias) se permiten, pues, pensar otras formulaciones sobre la subjetividad y la comunidad que trascienden los planteos identitarios y proyectar espacios queer que, notablemente, van en detrimento de cualquier posible delimitación territorial.

Es en este contexto, pues, que el mismo Perlongher publica su primer poema (firmado con el seudónimo "Gerardo"), en el que evidentemente se entrecruzan espacialidad (y movilidad) y disidencia sexual. Aparecido en el segundo número de Somos, "Defensa de los homosexuales de Tenochtitlán y Tlatlexlolco" (18) trasunta, como su título lo sugiere, un espíritu de solidaridad entre homosexuales de culturas y geografías diversas. Las culturas indígenas ocupan un lugar central allí donde Perlongher apela al mundo entero, redefinido y transformado, para poetizar en torno a una comunidad queer en ciernes, que atraviesa las épocas y las fronteras (se habla así de "tragedias griegas", "los aztecas", “ingleses", "Escocia”, "islas tropicales”, "princesas rusas”, etc.).

La retórica militante se vuelve evidente también desde el título. A primera vista, el poema parecería funcionar como suerte de ilustración o ejercicio literario a partir de la experiencia militante de la que Somos forma parte. Y hasta cierto punto es así: se trata de una "defensa" de un grupo ya definido (el de los "homosexuales") en situación de opresión (son "ahogados" o tomados como "víctimas expiatorias para los templos"), que adquiere visibilidad (de los "baños subterráneos" a los "parques soleados") y acaba por liberarse (con la final y triunfante salida por parte de un conjunto de aves -clara alusión a los 

Nostro Mundo: espacios extraordinarios en la poesía de Néstor Perlongher.

disidententes sexuales- de "zoológicos" y otros espacios de confinamiento). Al mismo tiempo, el poema es rico en sentidos y operaciones que van más allá de este planteo: lo que encontramos es una imaginación propositiva más que una mera "defensa"; los "homosexuales" son solo una entre varias formas de aludir a una extraña comunidad difusa y algo mutante a lo largo del poema; y aquellas "Tenochtitlán y Tlatexlolco" del título funcionan como una suerte de punto de partida de un viaje espacio-temporal que cuestionará las lógicas espaciotemporales convencionales.

En particular, el espacio es en este poema sometido a complejas operaciones que exceden en mucho las meras metáforas ligadas a la "liberación". Pese a que, como decíamos, el poema concluye con aquellas aves escapando del “zoológico" (y de las "ciudades sitiadas", y de las "fortalezas"), el verso "abandonan durante la noche los zoológicos sitiados" resulta ambiguo en la medida que ese "abandono" puede tener lugar de una vez y para siempre o bien describir un hábito cotidiano. Puede aludir a una liberación final o a una práctica que tiene lugar "durante la noche", como los yires nocturnos del "submundo homosexual" que a Perlongher gustaba frecuentar, analizar como antropólogo y plasmar poéticamente.

La mirada sobre el espacio es áerea y se mueve veloz, como la de un pájaro sobrevolando geografías distantes. El poema parece afirmar, así, un nomadismo homosexual coherente con ese interés transnacional al que nos hemos referido en relación a Somos. Se acumulan los circunstanciales de lugar ("en los baños", "en lo alto de las ciudades", "en torno a grandes lavarropas azules", "en sus oficinas", “de sus baños subterráneos", "en los acantilados de Escocia”, “en los parques soleados", “desde sus colchones fermentados", “en los zaguanes”, “en las ollas", "donde las mujeres de los aztecas resuelven los sacrificios de la cena", "a las cuadras donde los grandes campeones", que a cualquier lector avezado en la poesía de Perlongher le recordará a su célebre "Cadáveres") y los gentilicios diversos o las referencias a orígenes remotos ("tragedias griegas", "los aztecas", "nativos", “ingleses”, “de Escocia”, “princesas rusas”) que anticipan acaso el 
impulso exótico de la poética perlonghereana de años más tarde. El interés de Perlongher por la cartografía, que se volverá también más tarde una marca de su obra, despunta nítidamente con aquella mirada aérea que describe istmos, "islas", “campiñas", “fortalezas" y "acantilados de Escocia”.

Pero además, estos espacios se "barroquizan" - para utilizar un término caro a Perlongher- del mismo modo que el tiempo y los sujetos que lo habitan. No se trata solamente de una mirada aérea sino de operaciones que transgreden los ordenamientos y las representaciones geográficos habituales. El poema hace de la geografía un material plástico, maleable, más ligado a lo virtual, lo (im)posible, que a lo ya definido, lo ya conocido, lo ya dado. Veamos, si no, los espacios que irrumpen "cuando [a los homosexuales] les sea concedido el derecho a la caricia". Lejos de ser los destinos más o menos realistas de una liberación, se trata de espacios -se dirá después- "subjuntivos", "inexistentes": "saldrán de sus baños subterráneos con humeantes tazas de té entre las manos / en donde proyecten celestes espacios aires istmados de sofocantes islas tropicales / pobladas de dulces nativos cimarrones devastados tímidos por el inexplicable ataque de los cañones / ingleses, inexplicable!”. Ese espacio, el espacio de la liberación que reaparece más tarde con la repetición de los mismos versos como en una suerte de estribillo, es un espacio barroco: cada sitio es incluido como cajas chinas dentro de otro, o se escalona infinitamente hacia otro (además, el espacio se convierte en verbo: “istmar"). Finalmente, aparecen las "bellas extrañas islas inexistentes subjuntivas donde se mimetizan con los plumajes exóticos de grandes aves lujuriosas injustamente perseguidas / que abandonan durante la noche los zoológicos sitiados las fortalezas / las ciudades sitiadas que defienden los aztecas" (mis cursivas). Todo indica que el espacio de una liberación imaginada no puede sino arrastrar las características de lo imaginario.

Lejos de regodearse en la melancolía de una liberación imposible, sin embargo, el poema de Perlongher afirma la necesidad inconformista de pensar nuevos espacios (y tiempos) para una comunidad en proceso de formación. Volviendo a Muñoz, estos espacios subjuntivos podrían pensarse más como 
CATEDRAL TomadA: Revista de crítica literaria latinoamericana / Journal of Latin American Literary Criticism Nostro Mundo: espacios extraordinarios en la poesía de Néstor Perlongher.

potenciales que como posibles, existentes en potencia (o como potencia) en el presente de Gerardo/Perlongher. La geografía deja de ser un referente para la representación y se convierte, pues, en objeto de proyecciones, como sucede con aquellas tazas donde se "proyectan celestes espacios aires istmados de sofocantes islas tropicales" (mis cursivas). El poema opera pues en dos sentidos: por un lado, describe la superación de una situación de opresión por parte de sujetos anteriormente confinados e invisibilizados que pasan a "liberarse", en sintonía con las políticas del FLH y otros movimientos militantes alrededor del mundo; por el otro, afirma una fuerza simbólica o específicamente literaria para "proyectar" una comunidad alternativa, que habite otro tiempo y otro espacio, que impulse una redefinición de los tiempos y los espacios. Si bien estas exploraciones no fueron ajenas al FLH, tal como reflejan algunas zonas de la revista Somos, será en la poesía donde Perlongher se permitirá seguir indagando en las potencialidades de una imaginación espacio-temporal ligadas a una comunidad en formación. El advenimiento de la dictadura clausurará, además, la vía militante y lo forzará al exilio.

Esta imaginación espacial ligada a una utopismo queer se convierte, entonces, en una preocupación que acompañará a Perlongher a través de su obra, y definitivamente constituye una perspectiva a través de la cual es posible leerla. El primer poemario publicado por Perlongher, Austria-Hungría (1980) recurre al viejo imperio para introducir ordenamientos territoriales anacrónicos, opera a través de pliegues cartográficos (por ejemplo, el poema "La murga, los polacos" marca la irrupción de la cultura latinoamericana en una Polonia "que no es / que no es" -23) o establece puentes virtuales entre Buenos Aires y Montevideo ("Los orientales"), y lo más significativo es que esas intervenciones geográficas y espaciales propician escenarios potenciales para la sociabilidad de taxi-boys y de locas "tan derramadas, tan abiertas" ("Por qué seremos tan perversas, tan mezquinas" -56).

En todos estos ejemplos la proyección de formas de vida queer implica una exploración en torno a espacios alternativos, rechazando, como proponía el 
utopismo de Muñoz, el "aquí" entendido como espacio dado y ya intrínsecamente heteronormativo. En todos estos ejemplos, un cierto componente exótico (pensemos en las culturas precolombinas en "Defensa..." o en el anacrónico Imperio Austro-Húngaro) cumple una primera función de extrañamiento frente a los espacios habituales y da pie a una profusa imaginación espacial donde una incipiente comunidad queer puede tener lugar. Sin embargo, no será hasta los poemas más eminentemente neobarrocos o neobarrosos que el exotismo queer perlonghereano se nos mostrará - para retomar la cita del inicio- en su faceta más "rara", "linda", "joyesca".

\section{Exotismo neobarroso queer}

Es justamente para la época en que Perlongher conceptualiza el neobarroco a través de ensayos hoy ya célebres ("Cuba, el sexo y el puente de plata" -1986-, "La barroquización" -1988- y "Caribe Transplatino" -1991-) que lanza, a la vez, su célebre Parque Lezama (aparecido en 1990, luego de Hule, pero escrito antes que este y elaborado en la segunda mitad de la década del ochenta). Si el neobarroco funcionó, entre otras cosas, como una vía para formular otra geografía latinoamericana para una disidencia sexual desplazada de los imaginarios y territorios nacionales (en "Cuba, el sexo y el puente de plata”, la nómina de escritores neobarrocos entrecruza exilio y disidencia sexual de manera notable) no es casual que el poemario que más responde a la intervención perlonghereana en torno al neobarroco se llame Parque Lezama: lo que está en juego, como se evidencia en varios de sus poemas, es la proyección de un espacio imaginario, en alusión doble al poeta cubano, por un lado, y a un parque porteño, centro de cruising homosexual, por el otro. Un espacio subterráneo movilizando sociabilidades y sexualidades alternativas se formula 
CATEDRAL TomadA: Revista de crítica literaria latinoamericana / Journal of Latin American Literary Criticism Nostro Mundo: espacios extraordinarios en la poesía de Néstor Perlongher.

como una suerte de pliegue (o puente) entre lo barrial porteño y la algo distante cultura cubana.

Ahora bien, mientras que en los poemas neobarrocos de Alambres (1987) se concitan las culturas brasileña, uruguaya y argentina (y, nuevamente, se pliegan esos territorios), Parque Lezama (1990) trae consigo, a pesar del "puente" rioplatense-cubano del título, menos y más esporádicas alusiones a otras culturas latinoamericanas. Por otro lado, tampoco predominan las intervenciones sobre mapas y territorios existentes a la manera de Austria-Hungría (1980), ni los cruces o triangulaciones que los ensayos neobarrocos operan sobre el mapa latinoamericano (pienso especialmente en la idea de un "Caribe transplatino" que conecta el Río de la Plata y Cuba, formulada por Perlongher desde su estadía brasilera). Es que si bien en los ensayos de Perlongher sobre el neobarroco Latinoamérica aparece como región privilegiada, sus poemas más característicamente neobarrosos hacen lugar a otro tipo de exploraciones, que también apuntan a proyectar espacialidades alternativas para la disidencia sexual pero se sostienen sobre un mayor grado de abstracción y ponen en juego, sobre todas las cosas, una imaginación exótica o exotista.

¿Pero de qué se trata exactamente este exotismo? ¿Hasta qué punto conlleva -o no- nociones orientalistas, eurocéntricas, fetichistas de la diferencia? ¿De qué modo consigue habilitar sociabilidades y sexualidades queer?

Ya el primer poema de Parque Lezama nos introduce en la erótica exótica que le es característica. "Abisinia Exibar" reza su título, y una nota al pie nos explica que esa era la "marca de polvos usada por Lezama Lima" (187). La anécdota detrás de esta referencia cuenta que Lezama Lima recurría a aquellos polvos importados de Francia, de nombre particularmente exótico y extraño, para aliviar los síntomas del asma que padecía (la enfermedad y este tipo de remedios son tematizados célebremente en Paradiso) hasta que las autoridades cubanas impidieron su entrada al país, lo cual fue motivo de gran frustración para el escritor. Esta anécdota motoriza algunos de los sentidos recurrentes del poema, por ejemplo cuando se inmiscuyen algo socarronamente las quejas de un posible 
Lezama: “Exibar! No secuestren mis polvos que no voy a / dormirme” (189) o, casi al final, "me faltan los polvos, quiero saber quién los ha / cogido" (191). La alusión a la importación de este producto dispara toda una red de sentidos ligados al comercio ("mercaderes", "mercado", "a los polvos guarda en un / monedero" 188) y, como no debería extrañar en Cuba y el Caribe en general, especialmente al comercio marítimo ("naufragan", "velámenes"), lo cual a su vez nos remite a un sinfin de alusiones en torno al mar y a diversas sustancias líquidas ("Lago Negro", "licuación", "marinos", "mercurio", "leche agria", "cremosos", "piscina", "zambullido", "burbujas", "almibarados"): todo un campo semántico de la fluidez reforzado por permanentes aliteraciones ("Libio, lumina loas como jabas"). Por extensión, el mar y la predilección por lo líquido convocan, a su vez, toda una fauna (sub)marina ("peces", "medusa", "cetáceos") a través de la cual, como veremos, el poemario entero suele codificar sus alusiones al (sub)mundo homosexual.

"Abisinia exibar" trae consigo los sufijos latinos $a b$ y ex: movimiento hacia fuera $-e x$ nos interesa particularmente, porque está en la raíz etimológica de "exótico", "extraño" y "extranjero". El poema sugiere, pues, una tensión entre lo autóctono y lo que proviene de afuera, culminando con aquella voz lezamesca interesada en un producto de importación e indiferente a los símbolos patrios: "la patria tremola en la inmolación de los mancebos / pero yo quiero saber quién ha sido" (que retoma el verso ya citado: "y me faltan los polvos, quiero saber quién los ha / cogido" -191). No se trata solamente del país de procedencia de este polvo sino que podemos decir que todo exterior cobra aquí trascendencia, y funciona como una fuente de atracción o imantación afectando al poema de principio a fin. Los polvos de Lezama eran importados de Francia, pero sus ingredientes provenían de las colonias francesas -de hecho, Abisinia es un antiguo nombre árabe de la actual Etiopía. Además, el comercio marítimo trae consigo otros productos de importación: se mencionan así el ébano, proveniente de África y Asia, o "la hiel, [que] les ha venido de Dinamarca" -191-, y la aparición de un "baobab", árbol originario de África, Australia y la península 

Nostro Mundo: espacios extraordinarios en la poesía de Néstor Perlongher.

arábica e introducido en el Caribe durante el período colonial (al que también alude el poema: "el torno de ébano triza el esmalte / colonial" -188), colabora en la construcción de un paisaje cubano señalado en sus mezclas con otras regiones y culturas. De similar modo, proliferan también, como en tantos otros poemas de Perlongher, las alusiones algo arbitrarias a varios países ("italianos", "libio", "alemán", "Dinamarca" y en medio de ellas "Cuba") y las importaciones lingüísticas: mientras que en cierta forma el poema "transcurre" (o parte de una anécdota que tiene lugar) en Cuba y recrea la voz del cubano Lezama Lima, introduce a su vez palabras de otros idiomas como "ricercare" o "crepé". Aunque estos elementos no aparecen directamente justificados por el comercio marítimo, podríamos pensar que la importación del ébano, la hiel y los polvos de Lezama nos predisponen, ya, a figurarnos una Cuba permeable, abierta a estos intercambios transnacionales

Más interesante aún es cómo Perlongher, así como en otros momentos se interesa por el portuñol (en Alambres abundan los ejemplos, y pronto veremos otros ejemplos), en este primer poema de Parque Lezama combina español cubano (el uso de tú, la referencia a los "guajiros") con los guiños a un lunfardo argentino marcadamente erótico: "dientes con verguitas" (187), "alba de forro" (187), "troncha el pámpano el negro de un vergazo" (189), "la concha, polvos sulfurosos" (190), "y me faltan los polvos, quiero saber quién los ha cogido" (191), etc. Es que, como lo sugería Perlongher en "Caribe Transplatino", así como un "chongo" - expresado en lunfardo rioplatense- sale de aguas caribeñas en Maitreya de Sarduy, también en el propio neobarroso perlonghereano la mezcla lingüística suele darse mediante términos de contenido fuertemente sexualizado. Es significativo, pues, que el componente sexual provenga del recurso a la mezcla lingüística -una lengua singular y heterogénea que, como el título "Parque Lezama”, en principio va de lo barrial rioplatense a Cuba, pero no se agota allí. Perlongher despliega un conjunto de posibles alusiones sexuales no del todo evidentes, lo cual comienza a levantar sospechas sobre el resto del poema, y la energía erótica de algunos versos comienza así a diseminarse sobre el poema 
entero. El mismo término "polvo" es explotado aquí en su polisemia: como producto de importación, índice de una permeabilidad del afuera en el adentro, por un lado, pero también posiblemente como maquillaje (se hace referencia al "rimmel" en otro momento del poema) y como acto sexual según el habla popular argentina. Y si de referencias sexuales se trata, claramente predominan las homoeróticas: “iExibar! Pechos peludos, espejean tras las botellas. / Uno entra y le pide al tabernero un grifo. / Negros azules trocan sus guajiros" (190); luego, "Sin los polvos, soy un saurio rosa" dice el posible Lezama (191). No debemos perder de vista, al mismo tiempo, que las palabras extranjeras, y las mezclas de dialectos y argots, conviven con mecanismos neobarrocos que tienden al extrañamiento como el empleo de neologismos, de términos anticuados, el hipérbaton, la aliteración y muchos otros recursos de estilo. Este primer poema deja en claro, ya, de qué modo el erotismo que trae consigo Parque Lezama viene ligado a un extrañamiento radical, que no se limita ciertamente al "puente de plata" entre Cuba y Argentina. El "Caribe transplatino" funciona, en realidad, como punto de partida para una apertura cultural mayor, en la que predominan el exotismo entendido sobre todo como un desafío a la llamada "zona de confort", es decir, a los territorios y culturas conocidas y familiares. $\mathrm{Y}$ es en ese desafío a lo familiar que se habilita una "zona queer".

La Cuba de este y otros poemas de Parque Lezama parece reclamar un lugar curiosamente ausente en la Poétique de la relation de Édouard Glissant. La poética de la relación es particularmente visible, propone el filósofo martiniqués, en el área del Caribe, definida en gran medida por la convivencia y las mezclas de diferentes lenguas y culturas. En el centro del planteo de Glissant se ubica, fatal e imponente, el mar, superficie lisa por excelencia, al igual que en el poema inicial y buena parte de Parque Lezama. Glissant apunta además al barroco como una estética de "confluences" y "contaminations" (91), de las que Abisinia Exibar podría dar cabal cuenta. En "Poetics", el teórico antillano asocia al barroco como estética especialmente brasileña e hispanoaméricana, en línea con planteos de Lezama Lima, Alejo Carpentier, Sarduy y, como hemos visto, del mismo 
Perlongher: en Latinoamérica, la "poética de la relación” proviene según Glissant de "the explosion of the baroque expression, the same epic voice retying into the weft of the world" (35). Como recordaremos, en cada uno de estos cultores del neobarroco, algunos de los afluentes cruciales en esta "confluencia" barroca latinoamericana vienen dados por las diversas culturas indígenas de la región, o incluso podría deducirse de ellos que es la presencia indígena lo que ha vuelto al subcontinente latinoamericano especialmente proclive a los barroquismos. Por ejemplo, para explicar la pregnancia del neobarroco en Latinoamérica Sarduy la presenta como lo que hoy reconoceríamos como una zona de contacto: “Afrontado a los lenguajes entrecruzados de América -a los códigos del saber precolombino- el español, los códigos de la cultura europea se encontró duplicado, reflejado en otras organizaciones, en otros discursos" (21). Pero además, como sabemos que gustaba recordar Perlongher, esta Latinoamérica rica en heterogeneidades culturales abunda en variaciones dentro de la misma lengua española. Y en la propia poesía de Perlongher, cuando no se trata de combinar esos diferentes regionalismos, su lengua se muestra permeable a otras, entre las que se destaca, desde luego, el portugués.

Casi como si prolongaran aquella referencia al "chongo" saliendo del mar Caribe de Sarduy, en sus lecturas sobre Perlongher críticos como Brad Epps y Pablo Gasparini asocian mezcla cultural y disidencia sexual. Epps nos remite a la doble acepción del adjetivo "promiscuo" como "mezclado confusa o indiferentemente" y, dicho de una persona, "que mantiene relaciones sexuales con otras varias" para proponer que Perlongher participa de una "ética de la promiscuidad" (145). Aunque en su lectura Epps ahonda casi exclusivamente en las implicancias sexuales de esta "promiscuidad", demostrando cómo la poesía de Perlongher corroe los planteos de una identidad homosexual, fuertemente definida, homogénea y unívoca, también advierte que la promoción de una sexualidad impura puede asociarse a la tendencia en Perlongher hacia impurezas estéticas, culturales y lingüísticas. Gasparini, por su parte, se dedica a contrastar las mezclas habilitadas por el barroco del Siglo de Oro con aquellas propulsadas 
por Perlongher y, en particular, se detiene en aquel "gozoso portuñol" que despunta en varios de sus poemas:

Contra las preciosidades gongorinas y contra las esperanzas o utopías de modernización, se trataría aquí del trabajo con otra lengua no central, algo que, en todo caso, y desde una estética más ligada a la expresión que al discurrir [...] sólo podría compararse a César Vallejo (quien trabajó, o al menos reflexionó, además de con -o desde- el francés, con lenguas no cotizadas internacionalmente: el lituano, el polaco, el rumano y, por supuesto, el propio quechua). (760)

Gasparini analiza esta lengua de mezcla como expresión de su carácter extraterritorial y en sintonía con su tendencia a "profanar" los símbolos nacionales, “desvel[ando] [...] el carácter abyecto de lo santo; operación reversa que remite (de seguir la lectura de Freud en Moisés y la religión monoteísta) a todo lo que fue reprimido por el Padre: lo instintual, el sexo" (765). Así, para él el portuñol vehiculazaría, entre otras cosas, una suerte de desborde sexual respecto de las normativas de la patria.

Aunque del todo acertados, aportes como los de Epps y Gasparini sobre las mezclas culturales y su potencial queer no alcanzan a dar cuenta de los extrañamientos lingüísticos y culturales, espaciales y geográficos tan fundamentales en este y otros poemarios de Perlongher - extrañamientos también (neo)barrocos, e igualmente significativos desde una perspectiva genérico-sexual. Es en relación a esta serie de extrañamientos, propongo, que podemos analizar bajo una nueva perspectiva la profusa presencia de otras culturas y regiones en el neobarroco perlonghereano. Veamos, si no, las reflexiones del mismo Perlongher sobre las posibilidades estéticas del portuñol en su prólogo al libro de Wilson Bueno Mar paraguayo (uno entre varios textos que Perlongher dedicó al tema³):

\footnotetext{
${ }^{3}$ Véase también, por ejemplo, “El portuñol en la poesía”. Tsé Tsé, 2000, pp. 254-59.
} 
CATEDRAL Tomada: Revista de crítica literaria latinoamericana / Journal of Latin American Literary Criticism Nostro Mundo: espacios extraordinarios en la poesía de Néstor Perlongher.

Será que fue realmente Wilson Bueno quien 'inventó' el portuñol (un portuñol mechado de guaraní, que realiza por lo bajo, en la médula palpitante de la lengua, aquello que el poeta argentino -o, mejor, correntino- Francisco Madariaga invocaba desde las húmedas alturas de un surrealismo lujurioso: gaucho-beduino-afro-hispano-guaraní); o él, desde su altazor artístico, lo pegó, lo fue tomando de uno u otro fragmento de charla, banal, boba, con el mate en la mano y la china (o la rusa...) cebando, en sillitas bajas de paja, en el patio de atrás de la cocina.

Curiosamente, el libro de Bueno lleva el mar en su título, lo cual dispara en Perlongher una reflexión en sintonía con Deleuze y con Glissant: "las olas de este Mar son titubeantes, todo flota, como en una suspensión barroca, entre la prosa y la poesía, entre el devenir animal y el devenir mujer” (6). Así como sostiene que Bueno “inventó el portuñol”, esta lengua nunca es para Perlongher una mera reproducción de un habla ya existente sino una entre otras formas de intervención poética para lograr un importante y elaborado grado de extrañamiento. El portuñol interesa, sobre todo, como "mixtura aberrante", de “gramática sin ley” y “ortografía errática” basada en los desvíos, y, como el mar de Bueno que carece de "derrotero" alguno, puede llevarnos a otras mezclas que van más allá del portugués y del español. De ahí que para hablar de portuñol Perlongher enfatice la importancia del guaraní en la lengua de Bueno y, más aún, de aquel "gaucho-beduino-afro-hispano-guaraní" que invoca la cita. Lo que importa, entonces, en primer y último término, es extrañar la lengua, y en ese extrañamiento cumple un rol fundamental la extranjería: de ahí el despliegue de guiones ("gaucho-beduino-afro-hispano-guaraní") seguido de un curioso desplazamiento por el cual la "china", en principio mujer del gaucho, se 
orientaliza lúdicamente y nos remite a cualquier otra nacionalidad: "la china (o la rusa...)". Qué ha quedado del portuñol, cabe preguntarse. Posiblemente, propongo, su potencial como lengua exótica: una lengua "indecisa, intempestiva, mutante" que, en tanto tal, se arroja a formas todavía inexploradas.

Otra consideración por parte de Glissant en torno al barroco atañe, justamente, a su proclividad a lo oculto y lo desconocido: a diferencia del racionalismo, que concibe a la naturaleza como "harmonious, homogeneous, and thoroughly knowable", el barroco apuesta en cambio por la multiplicidad y aquello (aún) desconocido: "Baroque art was a reaction against the rationalist pretense of penetrating the mysteries of the known with one uniform and conclusive move. A baroque shudder, via this rerouting, set out to convey that all knowledge is to come and that this is what makes it of value" (77). Siguiendo esta lectura, la poesía de Perlongher sería barroca justamente en la medida que se mantiene en estado de apertura hacia lo desconocido y, en ese sentido, su permeabilidad hacia la otredad cultural se daría a la par de su atracción por lo extraño.

No es casual que Glissant refiera a Victor Segalen, uno de los escritores exotistas y teóricos sobre el exotismo más célebres, como uno de los mejores exponentes de la poética de la relación por la que aboga. Segalen concibe al exotismo como una "estética de la diversidad", en que la apertura a lo extranjero cifra una suerte de propulsión a lo extraño. Y es precisamente Segalen quien puede darnos algunas aproximaciones en torno al exotismo en la manera en que Perlongher lo explora en su propia obra literaria.

A través de sus notas para un libro nunca terminado, publicado póstumamente, en 1919, como Essay on Exoticism: An Aesthetic of Diversity, pero también mediante sus propios escritos en clave exótica, Segalen es conocido como quien procuró desligar al exotismo de sus versiones más adocenadas, como así también de su lógica imperial y colonialista: "sweep away [...] the colonial bureaucrat. They are nothing like Exots! [...] For the colonial Diversity exists only in so far as it provides him with the means of duping others" (35). Se trató, 
CATEDRAL Tomada: Revista de crítica literaria latinoamericana / Journal of Latin American Literary Criticism Nostro Mundo: espacios extraordinarios en la poesía de Néstor Perlongher.

para Segalen, de abrir el exotismo a nuevos sentidos y encontrar en él posibilidades nuevas; de "extend the notion of Exoticism" para concebirla como una "moving force" y "a vision of beauty" (16) a partir de la experiencia del shock (14) y otras sensaciones frente a aquello que al individuo le resulta poco habitual, diferente, ajeno. Así, de la experiencia con culturas remotas (a las que se abocó extensamente en su propia literatura), Segalen pasó a proponer otras posibles "fuentes" de exotismo (habla de "source[s] of nourishment"), entre las que incluye a los animales, el pasado o el futuro y, finalmente, "Everything [...] the ability to conceive otherwise" (16). Entre sus apuntes llegó a consignar incluso -aunque sin desarrollarlo- un posible "Extra-terrestrial Exoticism" (23). El "afuera" es, pues, clave en este planteo y por ello recurre al mismo prefijo al que nos referimos antes a propósito del primer poema de Parque Lezama: "Exo in the most general sense possible. Everything that lies 'outside"' (16).

Algunos otros aspectos nos interesan de estas notas dispersas y a veces contradictorias pero que en todo caso han habilitado interesantes enfoques, menos automáticos, en torno al exotismo y, ciertamente, pueden iluminar zonas de la poesía de Perlongher. Uno: como causa de esta búsqueda de lo exótico Segalen consigna un "failure to adapt to the surroundings" (17), de un modo similar al que la disidencia sexual en Perlongher implica un desajuste respecto de un "aquí" heteronormativo $\mathrm{y}$, tal vez por eso, su poesía tiende líneas de fuga hacia un “afuera". Dos: aunque en otra de sus notas aclara que se concentrará en el espacio, no deja de recordar que la sensación de exotismo puede experimentarse también en relación al tiempo: "historical exoticism: chronicles above all. Present: does not exist by definition. Future: Imaginary Exoticism" (16) y luego: "The Exoticism in Time. Going back: history. An escape from the contemptible and petty present. The elsewhere and the bygone days", o bien: "the future to come" (24). Como ocurre con "Defensa...", los poemas más queer de Perlongher suelen complicar la linealidad temporal -y no solo los órdenes espaciales vigentesapostando a un tiempo virtual en el que puede anidar, para retomar el planteo de José Muñoz, una cierta futuridad. Tres: para que producir estos efectos, lo exótico 
debe según Segalen permanecer exótico; no puede perder dicho estatuto. De similar modo, las referencias exóticas no funcionan en Perlongher como puertas de entrada a un verdadero conocimiento de culturas y regiones remotas; muy por el contrario, los elementos exóticos están allí para mantenerse en estado de exotismo, en función de un constante extrañamiento.

Aunque de acuerdo a varias lecturas la propia literatura de Segalen lo contradice en este último punto, afirmaciones semejantes recurren a lo largo de sus notas y cabe pensar que lo reenvían a aquel sesgo colonialista e imperialista que él mismo se proponía dejar atrás. Como decíamos, también en Perlongher lo exótico persiste en su exotismo: es poco (o nada) lo que aprendemos de China en sus menciones de China, o de Austria-Hungría en el poemario que lleva su nombre (resultará claro, por otra parte, que no es la aspiración de esta poesía el comunicarnos o representar una verdad última sobre estas culturas o regiones). Pero no menos cierto es que esta otredad a la que el otro parece condenado afecta de manera semejante cualquier atisbo de mismidad, de identidad en relación al yo poético, su lengua y todo marco cultural o geográfico que pudiera pensarse como propio. En otras palabras: como en el pliegue deleuzeano, lo interior también revela su propia exterioridad y es así que todo en Perlongher deviene exótico. No predomina, entonces, una lógica orientalista según la cual aquella otredad fetichizada como radical e insalvable diferencia sirve de sostén para la identidad de la cultura de pertenencia. Lo que está en juego, por el contrario, es la “otrificación” indiscriminada, incluso o primeramente de lo propio.

Como ya en este punto debe resultar evidente, una vez más la lengua cumple un rol esencial en este proceso de extrañamiento en el que lo propio se vuelve ajeno. Desde luego, lo que las notas de Segalen sobre el exotismo sugieren puede considerarse un claro precedente del concepto de ostranenie tal como lo entendió el formalismo ruso pocos años más tarde (Harootunian, Aravamudan, Aira). En "Lo exótico" y en "Lo incomprensible", César Aira en gran medida retoma los planteos de Segalen: "Los libros que amamos parecen escritos en una lengua extranjera", recuerda Aira la cita célebre de Proust en este último ensayo, 
CATEDRAL TomadA: Revista de crítica literaria latinoamericana / Journal of Latin American Literary Criticism Nostro Mundo: espacios extraordinarios en la poesía de Néstor Perlongher.

y agrega que, según él, dicha frase resume "la lógica del arte" ya que "la primera función del arte es extrañar, romper los hábitos de la percepción y volver nuevo lo viejo" (42). Una vez más, si bien el portuñol de Perlongher es indicativo de su opción latinoamericanista queer, de su proclividad por las mezclas y de su interés por conectar las culturas argentina (o hispana) con la brasileña, también funciona, simultáneamente, como una operación tendiente a extrañar -volver exóticasambas culturas y sus lenguas $-\mathrm{y}$, particularmente, la propia cultura y la propia lengua. Es importante también la sugerencia de Aira en "Lo incomprensible" de que las variedades linguiísticas dentro del idioma español a lo largo y ancho del continente latinoamericano funcionan como una suerte de unidad mínima exotista, en la medida que implican leves corrimientos respecto de las distintas lenguas nacionales ("el continente mismo se vuelve escritor, su lengua igual y diferente se vuelve literatura ready-made" ${ }^{4}$ ), todo lo cual podría retrotraernos a la compleja relación en Perlongher entre lo exótico y lo latinoamericano: palabras como “cremallera" o "taberna" en Parque Lezama implican, entre otras cosas, un efecto de extrañamiento.

Pero además, siguiendo los planteos de Sylvia Molloy en relación al escritor chileno de principios del siglo XX Augusto d'Halmar, conocido por su literatura exótica y por posar él mismo como sujeto (de lo) exótico, podemos pensar que también en Perlongher el exotismo habilita la irrupción de un "nosotros" (aquello que en la novela de d'Halmar Pasión y muerte del cura Deusto queda cifrado como "lo nuestro" dicho entre dos hombres que se aman) allí donde ninguna geografía ya dada parece inscribirlo. D’Halmar es, según

4 Prosigue Aira: "La frase de Proust tiene una maravillosa realización en los países hispanoamericanos. Si algo tuvo de bueno nuestra balcanización, fue generar veinte o treinta lenguas extranjeras dentro de la misma lengua. Los libros cubanos que amamos los argentinos parecen escritos en una lengua extranjera; claro, que para el buen lector argentino, Borges también parece escrito en una lengua extranjera. El continente, sus distancias y sus historias, reduplica el trabajo del escritor individual, y el continente mismo se vuelve escritor, su lengua igual y diferente se vuelve literatura ready-made" (42). Para profundizar sobre lo exótico en los ensayos y en la propia escritura de ficción de Aira, véase: Gutiérrez-Mouat, Ricardo. "César Aira y el exotismo". Cuadernos de Literatura, vol. 17, no. 34, 2013, pp. 250-62 
Molloy, un "viajero exótico, exponente del orientalismo eurocéntrico en su versión francesa" (246-47), quien goza de "una sólida reputación como una suerte de Pierre Loti sudamericano" (247); no obstante, en su caso, la disidencia sexual cumple un rol fundamental que nos obliga a lecturas alternativas sobre dicho orientalismo:

¿Por qué $[\ldots]$ no ver el recurso de d'Halmar al orientalismo (un orientalismo cuya explotación colonialista no pretendo negar) como la única manera de de crear un espacio para ese muy particular y muy secreto 'lo nuestro'? ¿Por qué no ver la elección de Sevilla, de una Sevilla exótica, de castañuelas y de incienso, como manera de crear un espacio de diferencia muy visible -muy espectacular, muy cursi- donde decir lo que no puede decirse en la ficción hispanoamericana de la época: un espacio extra-ordinario donde la homosexualidad no solo 'pasa' (aunque marginalmente) sino que puede pasar a la ficción? (259-260)

En suma, lo que está en juego, para Molloy, es la "manifest[ación] [d]el deseo homosexual en un 'afuera' exótico" (260). Un planteo no muy distinto al de José Muñoz en torno a la función de la utopía como impugnación de un "aquí y ahora" opresivo y en tanto apuesta por un futuro potencial para el desenvolvimiento de otras sociabilidades. Después de todo, si el exotismo à la Segalen puede aplicarse al tiempo, el futuro queer que Muñoz nos propone no es sino un futuro exótico. Esta digresión nos permite, entonces, retomar la poesía de Perlongher y entender por qué son precisamente aquellos poemas que más ahondan en sexualidades y comunidades alternativas los que, al mismo tiempo, se cargan de exotismos lingüísticos, culturales, temporales y -los que nos ocupan especialmente-espaciales y geográficos. Lo que Muñoz nos propone en cuanto al tiempo, esto es, encontrar en aquel rechazo al ahora la postulación de un tiempo otro, se replica de algún modo en la geografía perlonghereana: el desajuste respecto del "aquí" lleva a Perlongher a proyectar otros espacios. Y, como en 

Nostro Mundo: espacios extraordinarios en la poesía de Néstor Perlongher.

Muñoz, no se trata sencillamente de apostar por alternativas en todo contrarias al tiempo y el lugar propios sino también de operar por sobre los entresijos de esas coordenadas, extrañándolas: los modos alternativos de habitar ese "aquí y ahora" -los modos de volver ese "aquí y ahora" extraño, exótico, extranjero- abren ya nuevos espacios y nuevos tiempos.

Parque Lezama es reconocido, simultáneamente, como el poemario neobarroco de Perlongher por excelencia y, a su vez, como aquel donde da cuenta, como en ningún otro, de sus exploraciones poéticas y antropológicas en torno a sexualidades y sociabilidades queer (en él resuenan ideas, anécdotas y reportes de $O$ négocio do miche, publicado por Perlongher en Brasil solo unos pocos años antes). Pero, sobre todo, Parque Lezama es el poemario que mejor y más sistemáticamente representa los espacios existentes y habituales, o los espacios imaginarios, potenciales, siempre extraños/exóticos, donde esas sociabilidades y sexualidades pudieran desarrollarse. No es casual, como vengo arguyendo, que estas tres indagaciones sucedan en el mismo libro. La suerte de oda en prosa "Al miché" funciona como claro correlato de la investigación de Perlongher sobre la prostitución masculina: el tipo de escenas que su tesis describe, narra y/o razona aquí son "poetizadas" ("lucen las gambas si el doblón las dobla" comienza -231) para rápidamente derivar en otros sentidos, lisérgicamente, como en un "trip de jabas y malvones"). Lo que comienza como un episodio callejero nos lleva, también como un trip (viaje) en un sentido más literal, geográfico, a espacios que reescriben al modernismo latinoamericano: "cisnes negros, platean el lago viscoso y deletéreo, paúl oblicuo en el despiste de los 'puentes falsos', que conducían a la precipitación, al desparramo, al derrame de guantes de opalina" (231). No se trata solamente de desplazarse líquidamente, como en una embarcación (una prosa poética se llama "Kayak") por los mares ubicuos de Parque Lezama: se trata, también, de la transmutación de todo espacio en otro espacio posible -en este caso, de la calle al lago, y del lago, al "desparramo" y el "derrame"-; de la posibilidad de un espacio más o menos conocido de volverse exótico/extraño.

En "Cabezas peinadas", leemos: 
Las tres de cabezas peinadas / Se van al baile / Se van al baile / Al baile de Reveillon / Crepé y arroz /

y un alcanfor / discreto en la entretela / Croupier que rueda / bola de seda / en los senos de imitación / El sucedáneo. / Un buclecito / ¡Ay que se me descorre el el rouge! / ¡Pero pasame el kohol! (218)

Estas mujeres subrayadas en su artificio -y que por tanto nos remiten a las alusiones habituales a mujeres trans, travestis y drags en la poesía de Perlongherse preparan para ir "al baile", es decir que trasuntan una situación más o menos reconocible pero que, poco a poco, va recargándose de vectores exóticos a través de palabras importadas de otras lenguas y de objetos importados de otras regiones. El "kohol” (“¡Pero pasame el kohol!”) anuda varios significados y condensa la operación básica del poema, ya que se trata de una palabra árabe, proveniente del Antiguo Egipto, para designar el maquillaje de ojos utilizado por mujeres pero también por hombres en Oriente Medio, el Sur y el Norte de África y el Sur de Asia. Lo que circula entre las mujeres, posiblemente trans, o las drags del poema nos remite a geografías "remotas", “orientales", donde se desdibujan los ordenamientos de género de Occidente. Y luego, como en "Al miché” y la totalidad de los poemas de Parque Lezama, el paisaje vira a otro. A poco de mencionarse las “pirámides", leemos: "Panteón, Corinto, Edipo, Sfinge: / rutilan nombres grecorados / el decorado del revoque / en donde evoca el raído peplo / la ligera camisilla" (219). El artificio del maquillaje nos reenvía, pues, a la desnaturalización de los lugares, pero además esos lugares, tan orientales (Sfinge) como ligados a la cultura occidental (como lo demuestra la mención de Edipo), aparecen dotados de cierto allure extraño, exótico, y definitivamente distantes desde un punto de vista histórico. Como puede notarse, también, lo que puede (y suele) leerse como lengua travesti aquí y en varias zonas de la poesía perlonghereana -una lengua siempre presta a la mezcla lingüística- deja en verdad de ser más o menos identificable con un grupo social determinado para 
CATEDRAL TomadA: Revista de crítica literaria latinoamericana / Journal of Latin American Literary Criticism Nostro Mundo: espacios extraordinarios en la poesía de Néstor Perlongher.

mutar en una lengua marcadamente singular, que no es otra que la lengua poética que va construyendo Perlongher. Como se dice hacia el final: "Si era el rodar de su coyunda / entre las mezclas pizpiretas / la adaptación de la pintada / banda al inglés, al castellano, / runa gorjea, lela rima / agita el torpe peineteo, / el puro bucle de la pluma" (220).

Además de la calle, a lo largo de todo el libro aparecen otros sitios acostumbrados para el encuentro social y sexual entre michés, travestis, drag queens, chongos, locas, gays: baños, saunas, parques, fiestas, discotecas. Pero también, y sobre todo, las grutas, el trópico, la playa, el mar como espacios virtuales, artificiales, de ensoñación que nos recuerdan a aquellos "espacios de diferencia muy visible", "extra-ordinarios" a los que alude Molloy en relación a d'Halmar. La recurrencia de la preposición “en”, que nos remite inevitablemente a "Cadáveres", se convierte a esta altura en una seña característica de la poesía de Perlongher, $\mathrm{y}$ en este poemario antecede descripciones insospechadas: “Anochecer de un fauno" da comienzo "en el lácar lunado del espejuelo lácteo", “en élitro de libélula afilándose / en el filtro del lago: en el foco capcioso de esa luz china, pajarerías". En "Trópica” leemos: "El aire de los trópicos es denso / Reblandecidos chocolates medran / en esa densidad, / frutillas se relajan en la adherencia" (199, mis cursivas), espacios que rápidamente se cargan sexualmente: "en el vaho de las ingles", "Esos muslos torrados" (199). En este, como en varios otros poemas, los sujetos queer aparecen bajo la forma de peces $u$ otros animales marinos que han "huido de la pecera". En "La gruta" leemos:

en las escalinatas de 'vinilo' (y violo) / era la semiluz para el toco / de manotadas risáceas / alubias en el tronco de la ristra / o en el carajo emplumado / que alisa sus pencas de mimbres / y en vez de latiguear penetra / macizamente, la boca se abre como una gruta. (201)

En "Gomas, humos", las descripciones de un sauna gay ("los poros / se dilatan en el revoleo de las toallas" -207) viran, como en "Al miché", hacia 
espacios mucho más inciertos e indeterminados y así todas las alusiones a actos sexuales (el "frenesí", "las lluvias de un declive lácteo") pasan a transcurrir "en el vaho de las cruzadas y los pises", "en el regusto a engrudo", "en la muelle lanolina", "en el / anca que pende / incrustada en el fulcro / o en el precio" (207208, cursivas mías).

Todo el poemario se desarrolla, en verdad, como una investigación poética sobre "espacios extra-ordinarios" de sociabilidades y sexualidades alternativas. Suele suceder que eventos no del todo claros - pero a menudo brillantes, para retomar la cita de Perlongher del inicio, "espectaculares”, como decía Molloy- se desenvuelvan en espacios de características semejantes. Surgen como preguntas válidas, por tanto: ¿qué es lo que pasa? y ¿en dónde? “¿dónde? ¿atábase?” leemos en "Trópica"), si bien se deslizan por todos lados indicios eróticos y exóticos. En todo caso, importa señalar que, una y otra vez, las descripciones y narraciones de estas extrañas interacciones (queer) van acompañadas por una preocupación por los espacios igualmente extraños donde se desarrollan.

Es en este contexto que proliferan las alusiones a culturas de diferentes partes del mundo, en varios de los poemas ya señalados y en tantos otros: notablemente en "Lezama Boer" (donde la referencia Lezama se vuelve pretexto, como decíamos antes, para una excursión en clave orientalista), en "Pañuelo de los Moros", en "Danzig" (cuyo título, como Austria-Hungría, recurre a una cierta nostalgia geográfica por un tiempo en que los trazados limítrofes fueron distintos, a la vez que nos remite a una danza, o a la actividad en inglés, "dancing” para dar pie a descripciones de drag queens o mujeres exóticas, brillantes y espectaculares: "la rutilancia de la lentejuelas / en un rimmel de tan marmóreo transparente", “esfinge de codos revoloteantes y ampulosos" -192), en "Leyland" (donde la alusión al militante gay Winston Leyland -con quien el FLH supo mantener contactos- vuelve incierto cualquier anclaje a un determinado territorio: "no es en Liverpool donde la miradita se jaspea" -mis cursivas, 194) y un largo etcétera.

Como no podía ser de otra manera, incluso los espacios más familiares, como la casa, se vuelven "espacios extra-ordinarios", para seguir citando a 

Nostro Mundo: espacios extraordinarios en la poesía de Néstor Perlongher.

Molloy, una vez que adviene la posibilidad de un encuentro sexual en ellos. Veamos, si no, "El deshollinador", donde un yo poético planea llamar a un suplente de deshollinador, "un moreno aceitunado”, y se pregunta “¿He de seducir al deshollinador?"). Mediando el poema irrumpen referencias a bosques, como haciéndose eco del epígrafe de Girondo que da pie al poema ("Hay viejos árboles pederastas, florecidos en rosas de té”), y operaciones de extrañamiento sobre esos mismos paisajes: "no hay reverso, no pasamos de nuevo / por el lugar y sabemos que los árboles han sido comidos por los tapires" (197). Finalmente, cuando la carga erótica se eleva, el paisaje se torna definitivamente exótico y abstracto:

¿He de seducir al deshollinador / sólo para asegurarme del fracaso del trámite, / pues la chimenea se seguirá atascando, él atrapado en los ijares / y yo sorbiendo de la bota / con el sigilo que desata los cordones del ano con los dientes? / La lengua busca la caverna arenosa, hay barcos de ceibas haladas / En el retozo de las papilas en las lengüetas rosas / Abiertas como mariposas al lengüeteo de la mosca. (197-8)

Lo que muchas de estas citas parecen evocar es aquella "geografía erótica" que el mismo Rubén Darío propuso como clave de lectura para su "Divagación", un poema tan aéreo como varios de Perlongher (pensemos en "Defensa..." pero también en "Cadáveres"), que va moviéndose por diversas regiones y culturas para reclamar un cierto cosmopolitismo amoroso, teñido de un distintivo color local en cada caso. Como explica Mariano Siskind, "Divagación" funciona, a la vez, como un "world-mapping device", es decir, como un dispositivo mediante el cual el escritor modernista logra proyectar un mundo en el que insertar su propia literatura y, con ella, a una cultura latinoamericana que se pretende cosmopolita y moderna. La geografía erótica de Perlongher difiere en gran medida de la de Darío, no solo porque prevalece lo sexual (queer) por sobre lo amoroso sino, sobre todo, porque el mundo que nos presenta dista en mucho de sus representaciones habituales. Si bien no deja de ser interesante que en ambos casos 
el erotismo convoca desplazamientos geográficos y culturales, mientras que Darío construye un mundo a la medida de una agenda cosmopolita interesada en situar las letras latinoamericanas en la literatura mundial, la geografía de Perlongher se vuelve, sobre todo, un paisaje extraño, dúctil y pasible de transmutaciones. Los diferentes países y regiones se desdibujan, y cuando se retiene de ellos ciertos rasgos característicos, inmediatamente aparecen distorsionados o yuxtapuestos a otros que nada que ver tienen con ellos.

Además, en ocasiones es la misma geografía la que se carga de erotismo, prescindiendo de los sujetos o entrando en ensamblajes entre lo humano y lo no humano: el cuerpo se acopla o parece inseparable de los espacios que habitan. Eso es así, sobre todo, en las prosas poéticas del final del poemario. En "Caza”, por ejemplo, leemos: “(Piernas) [d]estiñen el furor glacial o decolorándolo, pozos de semiluz, como repliegues [...] ocultando los vellos al rocío" (228). En "Las grosellas": "ese muchacho claroscuro estira de su cuerpo napas de cutis que le penden del borde amarilleado de la uña", "el pellizo de glande en las mesetas ahora descampadas donde yace" y luego, "el túnel calloso de la sábana" (230). En "Urol": "Reporte muelle esquina láctea", “(una oruga arisca) yace en el estuario del tuco ácido alfombrado. Alegrías, asombros del que jala en la espesura de los vellos", "batallas navales en las anclas de los topacios, los pecíolos, incrustados en el ano" (232). En el ya mencionado "Kayak" partes del cuerpo aparecen acopladas tanto a accidentes geográficos como a espacios construidos por el hombre: fiordos, orillas, torrentes, ríos, playas, ramblas, escalinatas, cayos...

Finalmente, muchos de estos elementos se replican y alcanzan su máxima expresión en "“Nostro mundo", poema que ilustra como ningún otro las diversas indagaciones de Perlongher sobre "cómo urdir un territorio" para ese "mar de bolas" o "mar de cuerpos" que el mismo poema invoca. El título lo deja muy claro ya: entre comillas y a medio camino entre el italiano y el español, alude -acaso homenajea- al grupo pionero para el activismo homosexual en Argentina, antecedente del FLH. La dedicatoria, "Para Jorge Schwartz", autor del libro Vanguardia y cosmopolitismo antes mencionado que Perlongher gustaba en citar 
entre sus obras críticas preferidas, deja ver la intención de alumbrar en este poema un cierto impulso transnacional cifrado acaso en el nombre de la agrupación (Nuestro Mundo) y luego retomado más claramente la orientación internacionalista de su sucesor, el FLH. También es evidente que Perlongher considera aquí, como nosotros en la primera parte de este ensayo, la ambigüedad semántica de la expresión "nuestro mundo", que bien podía aludir al planeta Tierra o al "submundo" homosexual (la preocupación de Perlongher por estos espacios de sociabilidad queer específicamente era evidente, y se cifran por ejemplo en el poema de este mismo libro de título más que elocuente: "Ghetto"). Pero en este punto, y en línea con los planteos de varios de sus ensayos, la apuesta de Perlongher es transgredir las delimitaciones identitarias que pudieran anclar a los sujetos y sociabilidades queer en territorios determinados. La siguiente cita de "Nostro mundo"” ilustra muy bien, de hecho, la intención del FLH y, posteriormente, de Perlongher de pensar en una comunidad transversal en términos de clase, sensible a conflictos sociales más allá de lo estrictamente genérico-sexual y nunca limitada a las fronteras geográficas ya dadas: "cómo urdir un territorio / cuyas fronteras fueran tan lábiles que dejasen penetrar / el flujo de los suburbios y la huega de las panaderías matinales / el zaguán de la estela, ese temblor / de la alpaca en el mingitorio iluminado" (212).

El baño público aparece, pues, como espacio habitual de encuentros homosexuales, pero inmediatamente irrumpe el exotismo: el "mar de cuerpos", "las esfinges soleadas por el foco". Una geografía exótica, que luego deviene simplemente extraña (en este caso ficticia) y finalmente plástica: aquel "mar de bolas", "mar de cuerpos" en tanto homosexual es siempre un espacio remoto y abstracto, un "Mar Negro, o Blanco, tornasolado / a un rumor de escansiones sincopadas, / tornado suelo al pujo de una cresta de brines" (213).

Podría decirse que en este poema, en sintonía con el poemario en su totalidad y varias otras de sus intervenciones poéticas y ensayísticas, Perlongher da su propia versión de una posible sociabilidad queer. Lo que importa, entonces, de "Nostro mundo", o incluso, podríamos decir, de la experiencia del FLH, es la 
posibilidad constante y latente de imaginar una comunidad nunca del todo delimitada. De ahí la importancia de las "fronteras [...] lábiles". En este, como en varios otros poemas de Parque Lezama, los sujetos queer son comparados con peces y otros animales marinos (aparecen aquí, en este "mar de bolas" el tiburón, moluscos, caracolas), pero mientras que en algunos poemas insiste la pecera como uno entre tantos espacios de sociabilidad queer, en "Nostro mundo"” la geografía queer de Perlongher se inclina por formas predominantemente marítimas. La pecera y el mar, pues, como polos opuestos, pero reparando especialmente en todo aquello que transcurre entre ambos términos. Toda pecera (el sauna o las discotecas, por ejemplo, como espacios de anclaje para la sociabilidad queer) puede devenir en otra cosa, así como en "La gruta" la escena final donde se reúnen quienes tienen sexo con otros "mirones, agazapados" es vista como una "pecera fabulosa" (202), del mismo modo que la casa en "El deshollinador" (espacio cerrado por excelencia) puede derivar en una "travesía" hacia espacios insospechados y excitantes. De similar modo, los espacios abiertos siempre corren el riesgo de replegarse, y la apuesta por ellos se formula en todo caso como un cierto desafío, como un proyecto que acaso nunca pueda concretarse cabalmente, como planteo en suspenso: "cómo urdir un territorio / cuyas fronteras fueran [...] lábiles" se pregunta Perlongher.

Aquellas fronteras lábiles significan, pues, la necesidad de trascender la mirada identitaria, las delimitaciones de clase y también, sin duda, las inscripciones locales, familiares. De ahí que, una vez más, se trate de un poema abierto a otras culturas y geografías en clave exótica: "kohol”, "broderie", "zafiros", "arabescos". "Nostro mundo", al igual que Parque Lezama en general y buena parte de las intervenciones de Perlongher en relación a la disidencia sexual, deben leerse como la apuesta constante por imaginar esa sociabilidad de fronteras lábiles en más de un sentido; como un espacio y una geografía que, siempre desbordante respecto del territorio y la cultura ya dados, se proyecta a contrapelo de un aquí y ahora con los que la disidencia sexual no puede conformarse. 
Nota final: Agradezco las conversaciones con Gabriel Giorgi, Mary Louise Pratt, Laura Torres-Rodríguez y Cecilia Palmeiro, de las que salió buena parte de las ideas vertidas en este trabajo. También extiendo un agradecimiento a la Comunidad Homosexual Argentina por haberme facilitado los archivos de la revista Somos.

\section{Bibliografía}

Alexis. "Yo soy". Somos, 1974, pp. 38.

César Aira. "Lo incomprensible". El Malpensante, noviembre-diciembre de 1999, pp.42-3.

. "Exotismo". Boletín del Centro de Estudios de Teoría y Crítica Literaria, no. 3, 1993. pp. 73- 9.

Aravamudan, Srinivas. "Response: Exoticism beyond Cosmopolitanism?". Eighteenth Century Fiction, vol. 25, no. 1, 2001, pp. 1-7.

Brent Ingram, Gordon. "Marginality and the Landscapes of Erotic Alien(n)ations". Queers in Space: Communities, Public Places, Sites of Resistance, edited by Gordon Brent Ingram, Anne-Marie Bouthillette y Yolanda Retter, Bay Press, 1997, pp. 27-52.

[Declaración sin título]. Somos, 1973, pp. 2-3.

Epps, Bradley. "La ética de la promiscuidad: Reflexiones en torno a Néstor Perlongher". Iberoamericana, vol. 5, no. 18, 2005, pp. 145-164.

Freeman, Elizabeth. Time Binds: Queer Temporalities, Queer Histories. Duke, 2010.

Gasparini, Pablo. "Néstor Perlongher: Una extraterritorialidad en gozoso portuñol”, Revista Iberoamericana, vol. 76, no. 232-233, 2010, pp. 757775. 
Gerardo [Néstor Perlongher]. "Defensa de los homosexuales de Tenochtitlán y Tlatlexlolco", Somos, 1974, pp. 20-1.

Glissant, Edouard. Poetics of Relation. University of Michigan Press, 2010.

Gutiérrez-Mouat, Ricardo. "César Aira y el exotismo". Cuadernos de Literatura, vol. 17 , no. 34,2013 , pp. $250-62$

Harootunian, Harry. "The Exotics of Nowhere" (Foreword). Essay on Exoticism: An Aesthetic of Diversity, de Victor Segalen, Duke, 2002.

Molloy, Sylvia. Poses de fin de siglo: Desbordes del género en la modernidad. Eterna Cadencia, 2014.

Muñoz, José. Cruising Utopia: The Then and There of Queer Futurity. NYU Press, 2009.

Palmeiro, Cecilia. Desbunde y felicidad. De la Cartonera a Perlongher. Título, 2011.

Perlongher, Néstor. "El portuñol en la poesía”. Tsé Tsé, 2000, pp. 254-59. . Papeles insumisos. Santiago Arcos, 2004. . Poemas completos. Seix Barral, 1997. . Prosa Plebeya: Ensayos 1980-1992. Colihue, 2008. . "Sopa paraguaya” (prólogo), en Mar Paraguayo, de Wilson Bueno, TséTsé, 2005.

Sarduy, Severo. El barroco y el neobarro. El Cuenco de Plata, 2011.

Segalen, Victor. Essay on Exoticism: An Aesthetic of Diversity. Duke, 2002.

Siskind, Mariano. Cosmopolitan Desires: Global Modernity and World Literature in Latin America. Northwestern University Press, 2014. 